\title{
Evidence of Malnutrition and its Associated Factors among Under-five Children in Danko-Wasagu Kebbi State, North-western Nigeria
}

\author{
${ }^{* 1}$ S.B. Mada, ${ }^{1}$ K.D. Bawa, ${ }^{1}$ M.A. Saliu, ${ }^{1}$ A. Garba, ${ }^{1}$ M.M. Abarshi, ${ }^{1}$ A. Muhammad and ${ }^{2}$. Garba \\ ${ }^{1}$ Department of Biochemistry, Ahmadu Bello University, Zaria, Nigeria. \\ 2Department of Medical Microbiology, Usmanu Danfodiyo University Sokoto, Nigeria.
} ['Corresponding Author; E-mail: sbmada@abu.edu.ng]

\begin{abstract}
Malnutrition is a major health problem worldwide and causes about 2.3 million deaths among under-5 children in low- and middle-income countries annually including Nigeria. Therefore, the present study was designed to assess the nutritional status of under-five children (0-59 months) and associated factors in Danko-Wasagu. The socio-demographic characteristics, prevalence of childhood diseases, anthropometric parameters and dietary pattern of the children were evaluated. The results indicated that $54.8 \%$ of the caregivers are young adults within 20 to 24 years of age with $41.7 \%$ having two living children. In addition, $58 \%$ of the caregivers have monthly family income below $\$ 20,000$ with no any formal education. The Mid Upper Arm Circumference (MUAC) and Weight-for-Height (WFH) indices indicated that none of the children had Severe-Acute-Malnutrition (SAM). However, there was $65.5 \%$ prevalence of diarrhea, $45.2 \%$ with dermatitis and $25.0 \%$ with acute respiratory infections. In addition, stunting, underweight and wasting among the children investigated were $72.7 \%, 29.8 \%$ and $11.9 \%$ respectively. Consumption of cereals based diet by the children was $92.7 \%$ while $28.6 \%$ and $31.0 \%$ of the children met the minimum dietary diversity and minimum meal frequency respectively. Caregiver's age was observed to associate significantly $(p<0.05)$ with wasting, underweight and stunting among the children. Altogether, the present study demonstrated a high prevalence of chronic malnutrition and childhood diseases even though without any case of SAM in the study area.
\end{abstract}

Keywords: Malnutrition, Nutritional status, Under-five-children, Childhood diseases, Dietary pattern

\section{INTRODUCTION}

Malnutrition is a major health problem worldwide that threatens the wellbeing, health and survival of individuals particularly children under-five years of age. Nutritional status and child growth is universally accepted as a significant indicator of health and wellbeing of populations (WHO, 2010). Nutritional status of children under the age of five is particularly essential as it defines their health, optimal physical growth and development, school performance and advancement in life (Ruwali, 2011). According to World Health Organization (WHO), underweight is defined as weight for age (WFA) < -2 standard deviations (SD), stunting is defined as height for age (HFA) $<-2$ SD and wasting is defined as weight for height $(\mathrm{WFH})<-2 \mathrm{SD}$ which are the common indicators of malnutrition in children. Malnutrition influences morbidity and mortality among children in developing countries including Nigeria. Approximately 2.3 million mortalities among 6-59 months of age children in low- and middle-income countries are linked with malnutrition every year including Nigeria, which is around $41 \%$ of the total deaths in this age group (Sahu et al., 2015). Black et al. (2013) also reported that Moderate Acute Malnutrition (MAM) and Severe Acute Malnutrition (SAM) together account for around $11.5 \%$ of total deaths of children less than 5 years representing approximately 875,000 preventable deaths every year globally. Children should have access to adequate and quality nutrition which is crucial for attainment of the highest standard of health and living (WHO, 2004), proper organ functions, a robust immune system, and cognitive and neurological development (Purohit et al., 2017). Nutritional deficits have a long term effect on physical 
growth and development and may lead to increased level of illness and disability later in adult life (Badake et al., 2014). Ruwali (2011) also reported that malnutrition during childhood affects growth potential and increases the risk of morbidity and mortality in later years of life by affecting cognitive functions, contributes to poverty and hindered individuals' capability to attain productive live (De Onis et al., 2012). Thus, under-nutrition among children remains common in several parts of the world. According to WHO (2011), approximately 178 million children less than five years globally are too short for their age group; whereas 115 million are underweight. Similarly, in Africa and Asia, stunting rate among children is higher than any other region (WHO, 2011; Bhutia, 2014). In Nigeria, a survey conducted in 2018 by the Nigerian Nutrition Health Survey (NNHS), emphasized that the nutritional situation was 7\% wasting, $19.9 \%$ underweight, and 32\% stunting (NNHS, 2018).

Similarly, child malnutrition in developing countries have been linked to numerous and diverse factors including unreliable access to sufficient food, inappropriate dietary practices, insufficient health services, unhealthy environment, caregiver's socio-economic status and level of education among others (Bain et al., 2013; UNICEF, 2013). Therefore, multifaceted approaches and strategies are required to combat the ever increasing rate of malnutrition by comprehensively assessing the nutritional status of our local communities in order to provide information and support government programs policies and aim at combating childhood malnutrition. The study location was selected because it is less developed, has large number of rural population with inadequate health care facilities coupled with high rate of poverty (NNHS, 2018). Hence, the present study was designed to investigate the nutritional status of under-five children (0-59 months) and its associated factors in Danko-Wasagu Kebbi State, North-western Nigeria.

\section{MATERIALS AND METHODS Study Design}

The study was community based cross-sectional survey designed to assess the nutritional status of under-five children (0-59 months) and its associated factors in Danko-Wasagu, Kebbi State, Nigeria using a semi-structured questionnaire and measurements of weight, height and Mid Upper Arm Circumference (MUAC).

\section{Study Area}

Danko-Wasagu is one of the twenty-one (21) Local Government Areas (LGAs) of Kebbi State with headquarters at Ribah town located SouthSouth of the State and boarders with Zamfara and Niger States (Figure 1). Danko-Wasagu has an area of $4,016 \mathrm{~km}^{2}$ and a population of 265,271 (131,388 males and 133,883 females) base on 2011 National census. The LGA has two (2) chiefdoms, eight (8) districts and eleven (11) wards. The major tribes in Danko-Wasagu are Dakarkari, Hausawa, and Bangawa, and their major occupation is farming (substantial and peasant farmers).



Figure 1: Map of Kebbi State showing 21 Local Government Areas (Danko-Wasagu LGA circled in red)

\section{Sampling of Subjects}

Subjects included children under the age of 5 years and their mothers or principal caregivers (serving as the respondents) residing in selected settlements in Danko-Wasagu. Systematic 
sampling was used to select households while the sampling units for the study were households with children less than 5 years of age.

\section{Inclusion Criteria}

Children within 0-59 months and their caregivers in each household were included in this study.

\section{Exclusion Criteria}

Children (0-59 months) that were sick requiring hospitalization and those that are handicapped were excluded from the study. Those that declined consent were also excluded.

\section{Sample Size Determination}

A total sample size of one-hundred and ten (110) was estimated by using Dobson's formula at $95 \%$ Confidence interval $(t), n=t^{2}(p \times q) / d^{2}$ with $7 \%$ national prevalence rate $(p)$ of Global Acute Malnutrition (NNHS, 2018), 5\% desired level of significance (d) and 10\% non-response rate putting design effect of 1.0. ( $q=1-p)$.

$\mathrm{n}=1.96^{2}(0.07 \times 0.93) \div 0.05^{2}, \mathrm{n}=3.8416$ $(0.0651) \div 0.0025$

$n=100$, adding $10 \%$ non-response $n=110$.

\section{Data Collection}

A semi-structured questionnaire consisting of two sections was administered. The first section collected information on socio-demographic characteristics of the household. The second section collected information on the prevalence of childhood diseases among children and anthropometric data, which included age, sex, length/height, and weight and MUAC measurements of the children. Additionally, a food frequency questionnaire was administered to collect information on the dietary pattern of the children, minimum dietary diversity and meal frequency.

Child's age was obtained from the birth certificate, clinical cards or mother's recall or probe using historic landmark in case where the mother cannot recall. Children's weight was measured with light clothing using weighing scale adjusted in $100 \mathrm{~g}$ units. All children were weighed to the nearest $0.1 \mathrm{~kg}$. Length of children less than 24 months was measured using an infantometer (Model No. PE-AIM-101, USA). This was done on a stable and flat surface and the knees were held down and the head held firmly against the headboard. These measurements were done to the nearest $0.1 \mathrm{~cm}$. Children's (24-59 months) height was measured using a height board. This was done with the children standing erect without shoes, with eyes facing forward and the feet together on the horizontal plane. In addition, nutritional status of children was estimated from the degree of stunting (height-for-age), underweight (weight-for-age), wasting (weightfor-height) and MUAC following WHO guidelines (WHO, 1995) and comparing with WHO reference standard (WHO, 2006). In this study, a child was said to be severely underweight, wasted, and stunted if the WFA, WFH and HFA were <-3 Z-scores from the median of each international reference standard, respectively. Children with MUAC measurements of $<11.50$ $\mathrm{cm}, 11.50 \mathrm{~cm}-12.49 \mathrm{~cm}, 12.50 \mathrm{~cm}$ and above are severely malnourished, moderately malnourished and well-nourished respectively.

\section{Statistical Analysis}

Data were analyzed using the statistical package for social sciences (SPSS) IBM software version 22.0. Descriptive statistical analysis, percentages and frequencies were performed to summarize data. Analysis was stratified by age, sex and other characteristics. Bi-variate analysis was performed on various selected variables with nutritional indices of the children to determine the possible associations. P-value $<0.05$ was considered statistically significant.

\section{RESULTS}

Socio-demographic Characteristics of the Respondents in Danko-Wasagu

Although, a total of 110 caregivers each with their children from each household were included in this study, however only data for 84 respondents was reported due to incomplete data retrieved from the remaining semi-structured questionnaire. The result of socio-demographic 
characteristics revealed that majority of the caregivers 46 (54.8\%) were within the age range of $20-24$ years while only five $(6.0 \%)$ were within $15-19$ years (Table 1). Among the respondents, $35(41.7 \%)$ have two living children, $5(6.0 \%)$ have 4 , and $17(20.2 \%)$ have five living children and above. Similarly, most of the caregivers 61 $(72.6 \%)$ were affiliated to Islam religion while 23 (27.4\%) were Christians (Table 1). Moreover, the family monthly income of $49(58.3 \%)$ was below $\$ 20,000$ and none of the family earns above \#100,000. In terms of occupation, 47 (55.9\%) of mothers and $49(58.3 \%)$ of fathers were engaged in small-scale business, $5(6 \%)$ of mothers and $10(11.9 \%)$ of fathers were civil servants, while 32 $(38.1 \%)$ of mothers are full housewives, whereas $25(29.8 \%)$ of fathers are peasant farmers (Table 1). Likewise, mothers with no any formal education were $74(88.1 \%)$ while $10(11.9 \%)$ had primary education. In addition, $57(67.9 \%)$ of the fathers had no formal education, $4(4.8 \%)$ had primary education, while $10(11.9 \%)$ and 9 $(10.7 \%)$ attained secondary and tertiary education respectively (Table 1).

Table 1: Socio-demographic characteristics of respondents in Danko-Wasagu, Kebbi State

\begin{tabular}{ll}
\hline $\begin{array}{l}\text { Socio-demographic } \\
\text { Characteristics }\end{array}$ & $\begin{array}{l}\text { Frequency } \\
\text { (n= 84\%) }\end{array}$ \\
\hline $\begin{array}{l}\text { Caregiver's Age (years) } \\
15-19\end{array}$ & $5(6.0)$ \\
$20-24$ & $46(54.8)$ \\
$25-29$ & $8(9.5)$ \\
30 and above & $25(29.7)$ \\
Number of Living & \\
Children & \\
1 & $18(21.4)$ \\
2 & $35(41.7)$ \\
3 & $9(10.7)$ \\
4 & $5(6.0)$ \\
5 and above & $17(20.2)$ \\
Religion & \\
Islam & $61(72.6)$ \\
Christianity & $23(27.4)$
\end{tabular}

Others

$0(0.0)$

Family Monthly Income

Below 20,000

$49(58.3)$

$\# 21,000-\$ 50,000$

$26(31.0)$

$\$ 51,000-\$ 100,000$

$9(10.7)$

Above $\$ 100,000$

$0(0.0)$

Mother's Occupation

Housewife

32 (38.1)

Business

$47(55.9)$

Civil servant

$5(6.0)$

Others

Father's Occupation

Farmer

25 (29.8)

Business

49 (58.3)

Civil servant

$10(11.9)$

Others

$0(0.0)$

\section{Education Level of Mother}

No formal education

74 (88.1)

Primary

$10(11.9)$

Secondary

$0(0.0)$

Tertiary

Others

$0(0.0)$

\section{Education Level of Father}

No formal education

Primary

$57(67.9)$

Secondary

$10(11.9)$

Tertiary

9 (10.7)

Others

$4(4.8)$

Values are number (\%) unless otherwise stated

\section{Anthropometric Data of Children (0-59} months) in Danko-Wasagu

Among the under-five children included in this study, $8(9.5 \%)$ are within the age range $0-11$ months while $21(25.0 \%), 15(17.9 \%), 26(31.0 \%)$ and $14(16.7 \%)$ were in the age ranges of $12-23$, 24-35, 36-47 and 48-59 months respectively (Table 2). The number male children were larger $45(53.6 \%)$ than female children 39 (46.4\%). Also, the mean height and weight for male children were $84 \pm 11 \mathrm{~cm}$ and $14 \pm 6 \mathrm{~kg}$ respectively, whereas female children were $82 \pm 11 \mathrm{~cm}$ and $13 \pm 4 \mathrm{~kg}$ respectively for height 
and weight (Table 2). Interestingly, based on the MUAC measurements, none of the under-five children investigated had severe-acutemalnutrition (SAM), although $13(15.5 \%)$ within the age range of 36-47 months were moderately malnourished (MAM) out of which $61.5 \%$ were females and $(38.5 \%)$ males. Interestingly, 71 $(84.5 \%)$ of the children are well-nourished with $29.6 \%$ are within age range of $12-23$ months (Table 2).

Prevalence of Childhood Diseases Among Children (0-59months) in Danko-Wasagu

Childhood disease is another determinant factor for assessment of nutritional status in children. Among the children investigated, $55(65.5 \%)$ had one or more cases of diarrhea while $38(45.2 \%)$ had dermatitis and $21(25.0 \%)$ had acute respiratory infection two weeks before the study (Table 3).

Nutritional Status of Under-five Children (0-59 months) in Danko-Wasagu

Analyses of data on the nutritional status of children (0-59 months) in Danko-Wasagu according to WFH, WFA and HFA revealed that none of the children was either severely or moderately wasted on the basis of WFH, although $10(11.9 \%)$ were mildly wasted and 74 $(88.1 \%)$ were normal; the normal children were within the age range of 36-47 months (Table 4). The results also indicated for WFA, $9(10.7 \%), 4$ $(4.8 \%)$ and $12(14.3 \%)$ were severely, moderately and mildly underweight respectively, implying that $25(29.8 \%)$ of the children were underweight and $59(70.2 \%)$ were normal (Table 4$)$.

Table 2: Anthropometric indices of under-five children in Danko-Wasagu, Kebbi State

\begin{tabular}{|c|c|c|c|c|}
\hline \multirow[b]{2}{*}{ Variables } & \multirow[b]{2}{*}{$\begin{array}{l}\text { Frequency } \\
(n=84)\end{array}$} & \multicolumn{3}{|c|}{ MUAC measurements $(\mathrm{cm})$} \\
\hline & & $\begin{array}{c}<11.50 \\
(\%)\end{array}$ & $\begin{array}{c}11.50-12.49 \\
(\%)\end{array}$ & $\begin{array}{l}12.50 \text { and above } \\
(\%)\end{array}$ \\
\hline \multicolumn{5}{|l|}{ Age (months) } \\
\hline $0-11$ & $8(9.5)$ & 0.0 & 30.8 & 5.6 \\
\hline $12-23$ & $21(25.0)$ & 0.0 & 0.0 & 29.6 \\
\hline $24-35$ & $15(17.9)$ & 0.0 & 0.0 & 21.1 \\
\hline $36-47$ & $26(31.0)$ & 0.0 & 69.2 & 23.9 \\
\hline $48-59$ & $14(16.7)$ & 0.0 & 0.0 & 19.7 \\
\hline \multicolumn{5}{|l|}{ Sex } \\
\hline Male & $45(53.6)$ & 0.0 & 38.5 & 56.3 \\
\hline Female & $39(46.4)$ & 0.0 & 61.5 & 43.7 \\
\hline \multicolumn{5}{|l|}{ Height (cm) } \\
\hline Male & $84 \pm 11^{*}$ & & & \\
\hline Female & $82 \pm 11^{*}$ & & & \\
\hline \multicolumn{5}{|l|}{ Weight (kg) } \\
\hline Male & $14 \pm 6^{*}$ & & & \\
\hline Female & $13 \pm 4^{*}$ & & & \\
\hline \multicolumn{5}{|c|}{ MUAC measurements $(\mathrm{cm})$} \\
\hline$<11.50$ & $0(0.0)$ & & & \\
\hline $11.50-12.49$ & $13(15.5)$ & & & \\
\hline 12.50 and above & $71(84.5)$ & & & \\
\hline
\end{tabular}

Values are number (\%) unless otherwise stated; *Values are Mean \pm SD. 
Nigerian Journal of Basic and Applied Science (June, 2020), 28(1): 56-65

Table 3: Prevalence of childhood diseases of under-five children in Danko-Wasagu, Kebbi State

\begin{tabular}{lll}
\hline $\begin{array}{l}\text { Childhood } \\
\text { Diseases }\end{array}$ & & $\begin{array}{c}\text { Frequency } \\
(\mathbf{n}=84)\end{array}$ \\
\hline Diarrhea & Yes & $55(65.5)$ \\
& No & $29(34.5)$ \\
Dermatitis & Yes & $38(45.2)$ \\
& No & $46(54.8)$ \\
Acute & Yes & $21(25.0)$ \\
Respiratory & No & $63(75.0)$ \\
Infections & & \\
\hline
\end{tabular}

Values are number (\%) unless otherwise stated

However, none of the male children was severely or moderately underweight; all $(100 \%)$ moderately underweight while $66.7 \%$ are mildly underweight children. Severely underweight children $(55.6 \%)$ were within the age range of 2435 months (Table 4). Based on the HFA, all $(100 \%)$ of the children were stunted, $35(41.7 \%)$ were severely stunted while $26(31.0 \%)$ and 23 $(27.4 \%)$ were moderately and mildly stunted respectively (Table 4). Similarly, $84.6 \%$ of moderately stunted children were females whereas $51.4 \%$ of severely stunted children were males. Equally, $61.5 \%$ and $43.5 \%$ of moderately and mildly stunted children respectively were within the age range of 36-47 months while $48.6 \%$ of severely stunted children were within the age range of 12-23 months (Table 4).

Dietary pattern of under-five children (0-59 months) in Danko-Wasagu

Most of the under-five children (92.7\%) investigated consumed cereals food group (Figure 2), while $47.6 \%$ consumed vegetables, $34.6 \%$ consumed roots and tubers, $26.2 \%$ consumed legumes, nuts and seeds food (Figure 2). Similarly, consumption of flesh food and dairy products were $12.0 \%$ and $10.8 \%$ respectively. Eggs, fruits and vegetables were the least consumed with $4.8 \%$ each (Figure 2). Data revealed only $28.6 \%$ of the subjects met the minimum dietary diversity requirements by consuming food from at least four different food groups the previous day (Figure 3 ) while $31.0 \%$ met daily required minimum meal frequency (Figure 4).

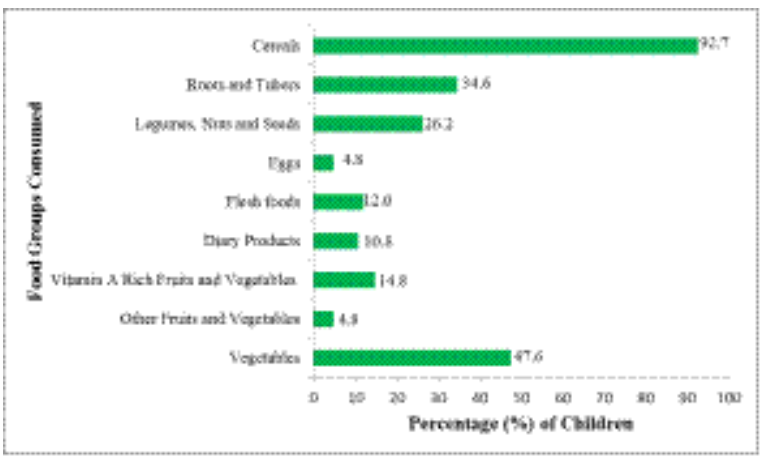

Figure 2: Distribution of food groups consumed by under-five children in Danko-Wasagu

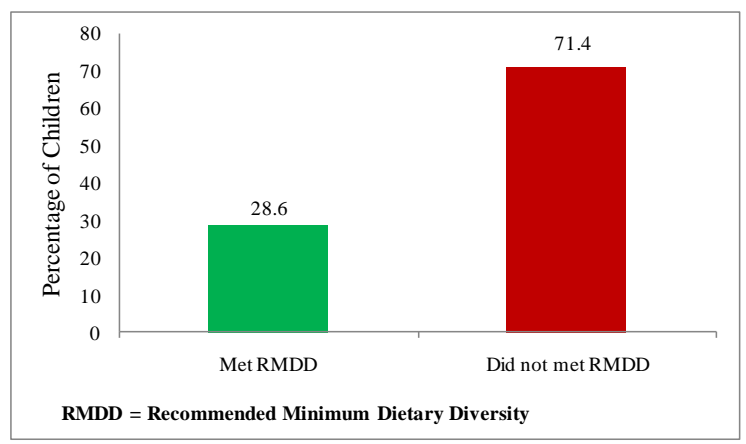

Figure 3: Minimum dietary diversity of under-five children in Danko-Wasagu

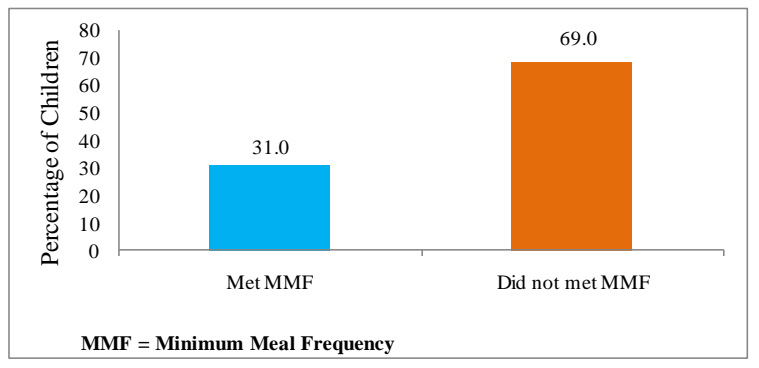

Figure 4: Minimum meal frequency of under-five children in Danko-Wasagu 
Mada et al: Evidence of Malnutrition and its Associated Factors among Under-five Children

Table 4: Nutritional status of under-five children (0-59 months) in Danko-Wasagu, Kebbi State

\begin{tabular}{|c|c|c|c|c|c|c|c|c|c|c|c|c|}
\hline \multirow{2}{*}{$\begin{array}{c}\text { Nutritional } \\
\text { Status } \\
(n=84)\end{array}$} & \multicolumn{4}{|c|}{ WFH (Wasting) $\%$} & \multicolumn{4}{|c|}{ WFA (Underweight) $\%$} & \multicolumn{4}{|c|}{ HFA (Stunting) $\%$} \\
\hline & SW & MOW & MIW & Normal & SU & MOU & MIU & Normal & SS & MOS & MIS & Normal \\
\hline \multicolumn{13}{|l|}{$\begin{array}{l}\text { Age } \\
\text { (months) }\end{array}$} \\
\hline $0-11$ & 0.0 & 0.0 & 0.0 & 10.8 & 0.0 & 0.0 & 33.3 & 6.8 & 11.4 & 0.0 & 17.4 & 0.0 \\
\hline $12-23$ & 0.0 & 0.0 & 0.0 & 28.4 & 0.0 & 100 & 66.7 & 15.3 & 48.6 & 0.0 & 17.4 & 0.0 \\
\hline $24-35$ & 0.0 & 0.0 & 50.0 & 13.5 & 55.6 & 0.0 & 0.0 & 16.9 & 0.0 & 38.5 & 21.7 & 0.0 \\
\hline $36-47$ & 0.0 & 0.0 & 0.0 & 35.1 & 0.0 & 0.0 & 0.0 & 44.1 & 0.0 & 61.5 & 43.5 & 0.0 \\
\hline $48-59$ & 0.0 & 0.0 & 50.0 & 12.2 & 44.4 & 0.0 & 0.0 & 16.9 & 40.0 & 0.0 & 0.0 & 0.0 \\
\hline \multicolumn{13}{|l|}{ Sex } \\
\hline Male & 0.0 & 0.0 & 50.0 & 54.1 & 0.0 & 0.0 & 66.7 & 62.7 & 51.4 & 15.4 & 100 & 0.0 \\
\hline Female & 0.0 & 0.0 & 50.0 & 45.9 & 100 & 100 & 33.3 & 37.3 & 48.6 & 84.6 & 0.0 & 0.0 \\
\hline Total $^{*}$ & $\begin{array}{c}0 \\
(0.0)\end{array}$ & $\begin{array}{c}0 \\
(0.0)\end{array}$ & $\begin{array}{c}10 \\
(11.9)\end{array}$ & $\begin{array}{c}74 \\
(88.1)\end{array}$ & $\begin{array}{c}9 \\
(10.7)\end{array}$ & $\begin{array}{c}4 \\
(4.8)\end{array}$ & $\begin{array}{c}12 \\
(14.3)\end{array}$ & $\begin{array}{c}59 \\
(70.2)\end{array}$ & $\begin{array}{c}35 \\
(41.7)\end{array}$ & $\begin{array}{c}26 \\
(31.0)\end{array}$ & $\begin{array}{c}23 \\
(27.4)\end{array}$ & $\begin{array}{c}0 \\
(0.0)\end{array}$ \\
\hline
\end{tabular}

* Values are number (\%) unless stated otherwise. SW=Severe Wasting, MOW=Moderate Wasting, MIW=Mild Wasting, SU=Severe Underweight, MOU=Moderate Underweight, MIU=Mild Underweight, SS=Severe Stunting, MOS=Moderate Stunting, MIS=Mild Stunting. Severely malnourished $=<-3 S D$; moderately malnourished $=<-2 S D$ to $\geq-3 S D$; mildly malnourished $=<-1 S D$ to $\geq-2 S D ;$ Normal $=\geq-1 S D$.

Factors Associated with Nutritional Status of Children (0-59 months) in Danko-Wasagu

The proportion of under-five children (059months) who were malnourished (wasting) showed significant $(p<0.05)$ association with caregiver's age, level of mother's education, monthly family income and minimum dietary diversity. However, mother's occupation, childhood disease and minimum meal frequency were not significantly $(p>0.05)$ associated with wasting among the under-five children investigated (Table 5). Similarly, the number of children who were underweight showed significant $(p<0.05)$ relationship with caregiver's age, mother's occupation, childhood disease and minimum dietary diversity. Mother's level of education, monthly family income and minimum meal frequency were not significantly $(p>0.05)$ related with underweight among the under-five children as shown in Table 5. Additionally, there was significant $(p<0.05)$ connection between proportion of stunted children with caregiver's age, mother's occupation, education level, childhood disease, monthly family income and minimum meal frequency. Conversely, there was no significant $(p>0.05)$ association with minimum dietary diversity (Table 5).

Table 5: Some selected factors associated with nutritional status of under-five children in Danko-Wasagu

\section{Chi-Square $p$-value}

\begin{tabular}{lccc}
\hline Variables & WFH & WFA & HFA \\
\cline { 2 - 4 } Caregiver's Age & $0.000^{*}$ & $0.017^{*}$ & $0.000^{*}$ \\
Mother's Occupation & 0.557 & $0.003^{*}$ & $0.011^{*}$ \\
Education Level of Mother & $0.000^{*}$ & 0.186 & $0.000^{*}$ \\
Family Monthly Income & $0.017^{*}$ & 0.068 & $0.000^{*}$ \\
Childhood Diseases (Diarrhea) & 0.273 & $0.037^{*}$ & $0.000^{*}$ \\
Minimum Dietary Diversity & $0.019^{*}$ & $0.017^{*}$ & 0.890 \\
Minimum Meal Frequency & 0.130 & 0.190 & $0.000^{*}$ \\
\hline
\end{tabular}

*Values are statistically significant at $p$-value $<0.05$. 


\section{Nigerian Journal of Basic and Applied Science (June, 2020), 28(1): 56-65}

\section{DISCUSSION}

This study investigated the nutritional status of under-five children (0-59 months) and its associated factors in Danko-Wasagu, Kebbi State. Most of the caregivers are young adults with age range between 20 to 24 years and majorities are having two living children. About $58.3 \%$ of the respondents earn below $\$ 20,000$ in a month (less than US $\$ 1.90$ per day) which indicates a high level of poverty in the family. The monthly family income and caregiver's level of education might have profound effect on the nutritional status of their children. There was no much variation in the height and weight among the male and female children. However, acute malnutrition based on MUAC measurements revealed zero percent SAM in the WFH index data but $15.5 \%$ MAM was observed which was higher than $5.9 \%$ reported for Kebbi State by the NNHS survey in 2018 but much closer to $10.0 \%$ reported in 2015 (NNHS, 2015; NNHS, 2018). This discrepancy may be explained by the fact that this study was conducted during dry season and there was a high prevalence of diarrhea among the children. One of the immediate causes of malnutrition in children is infectious diseases alongside inadequate dietary intake (UNICEF, 2013). In this study, there was prevalence of childhood diseases among the under-five children with a prevalence of $65.5 \%$ for diarrhea, $45.2 \%$ for dermatitis and $25.0 \%$ with acute respiratory infections. These diseases may cause loss of appetite as well as reduce absorption and utilization of foods consumed by these children leading to malnutrition; nevertheless, the present data revealed that none among the under-five children investigated had any form of severe and moderate wasting, though $11.9 \%$ of the children were mildly wasted.

The indices for both acute and chronic malnutrition are weight-for-height (WFH), weightfor-age (WFA), and MUAC measurements. The present findings revealed a prevalence of $29.8 \%$ of underweight, which is just 0.2 points below the $30 \%$ of WHO critical threshold and $10.7 \%$ reported case of severe underweight. Thus findings in this studies are consistent with previous report for Kebbi State by the NNHS survey conducted in 2018 with prevalence of underweight and severe underweight at $32.8 \%$ and $9.6 \%$ respectively (NNHS, 2018). We demonstrated that $72.7 \%$ of the children in Danko-Wasagu were stunted, out of which 41.7 $\%$ and $31.0 \%$ were severely and moderately stunted respectively. The prevalence of stunting in this population was very high and above the WHO critical threshold $40 \%$ and above. In addition, when compared with $51.8 \%$ and 19.0 $\%$ for prevalence of stunting and severe stunting respectively in Kebbi State, the prevalence of stunting is higher while that of moderate stunting was similar at $32.8 \%$ (NNHS, 2018). This high prevalence of stunting is a long term effect of malnutrition in the population and can also be attributable to other factors including insufficient protein and energy intake, frequent infection or illness, inappropriate feeding practices and poverty over long period (WHO, 2018). Dietary pattern is another aspect that influences the nutritional status of children particularly underfive years. The present study reported high $(92.7 \%)$ consumption of cereals food group by the children which met their requirements for macronutrients but not their micronutrients which are equally essential for growth and development. For instance, eggs, and other fruits and vegetables were least (4.8\%) consumed by the children which obviously can lead to micronutrient deficiency with negative impact on their nutritional status as well as utilization of macronutrients in their body. Also, $71.4 \%$ of the children did not meet the minimum dietary diversity of consuming four different food groups possibly due to economic reasons or because lack of availability and accessibility to different food groups in those communities. In the same way, the minimum meal frequency was low $(31.0 \%)$ showing that majority of the children did not eat the recommended minimum number of times. All these can have negative effects on the nutritional status of the children. The present study also established the association between 
Mada et al: Evidence of Malnutrition and its Associated Factors among Under-five Children. nutritional status indices (stunting, wasting and underweight) and some socio-demographic characteristics such as caregiver's age, mother's occupation, level of mother's education and monthly family income, and childhood diseases, minimum dietary diversity and minimum meal frequency. Caregiver's age was significantly associated with wasting, underweight and stunting and it has been reported in several studies that children of older mothers are less likely to suffer from malnutrition, whereas young maternal age is associated with high prevalence of malnutrition (Nyaruhucha et al., 2006). Mother's occupation was associated with underweight and stunting in this study. Nutritional and health status of children can be severely affected by their mothers' occupation (Abbir et al., 2006) possibly because the care needed by the children from working-class mothers may be hindered due to time constraints (Kalu and Etim, 2018).

Maternal education is another factor affecting nutritional status of children and it was found that level of mother's education was associated with wasting and stunting in under-five children. Mothers/caregivers quality of care given to children is influenced by the mothers' knowledge of proper nutrition and child health care practices (Halder and Kejriwal, 2016). Reduced or poor household income may lead to less expense on the food (Kalu and Etim, 2018). This study showed that, monthly family income was associated with wasting and stunting. Moreover, childhood disease was associated with underweight and stunting among the malnourished children and it has been established that disease is one of the cause of malnutrition especially when there is susceptibility (UNICEF, 2013). Consumption of diversified diet or different food groups and eating the recommended minimum number of times has profound effects on the nutritional status of children. Findings from this study demonstrated an association between minimum dietary diversity with wasting and underweight among the under-five children whereas minimum 


\section{Nigerian Journal of Basic and Applied Science (June, 2020), 28(1): 56-65}

Bhutia, D. T. (2014). Protein energy malnutrition in India: the plight of our under five children. Journal of family medicine and primary care, 3(1): 63-67.

Black, R. E., Victora, C. G., Walker, S. P., Bhutta, Z. A., Christian, P., De Onis, M., ... \& Uauy, R. (2013). Maternal and child undernutrition and overweight in lowincome and middle-income countries. The lancet, 382(9890): 427-451.

De Onis, M., Brown, D., Blossner, M., \& Borghi, E. (2012). Levels and trends in child malnutrition. UNICEF-WHO-The World Bank joint child malnutrition estimates.

Halder, S., \& Kejriwal, S. (2016). Nutritional awareness of mothers in relation to nutritional status of the preschool children. Early Child Development and Care, 186(9): 1366-1377.

Kalu, R. E., \& Etim, K. D. (2018). Factors associated with malnutrition among underfive children in developing countries: A review. Global Journal of Pure and Applied Sciences, 24(1): 69-74.

NNHS. (2015). Report on the nutrition and health situation of Nigeria. National Nutrition and Health Survey: 1-141.

NNHS. (2018). Report on the nutrition and health situation of Nigeria. National Nutrition and Health Survey: 1-152.

Nyaruhucha, C. N., Msuya, J. M., Mamiro, P. S., \& Kerengi, A. J. (2006). Nutritional status and feeding practices of under-five children in Simanjiro District, Tanzania. Tanzania Journal of Health Research, 8(3): 162-167.

Purohit, L., Sahu, P., \& Godale, L. B. (2017). Nutritional status of under-five children in a city of Maharashtra: a community based study. International Journal of Community Medicine and Public Health, 4(4): 1171-1178.

Ruwali, D. (2011). Nutritional status of children under-five years of age and factors associated in padampur vdc, chitwan. Health Prospect, 10: 14-18.
Sahu, S. K., Kumar, S. G., Bhat, B. V., Premarajan, K. C., Sarkar, S., Roy, G., \& Joseph, N. (2015). Malnutrition among under-five children in India and strategies for control. Journal of natural science, biology, and medicine, 6(1): 18-23.

Unicef. (2013). Improving child nutrition: the achievable imperative for global progress. New York: UNICEF, 1-14.

WHO, I. (2004). Child and Adolescent Health and Development Progress Report 20022003. France. WHO Library Cataloguingin-Publication Data, 10-17.

WHO, M. (2006). Growth, Reference, Study, Group. WHO Child Growth Standards: Length/height-for-age, weight-for-age, weight-for-length, weight-for-height and body mass index-for-age: Methods and development. Geneva: World Health Organization.

WHO. (2011) World Health Statistics. World Health Organization, Geneva, Switzerland.

WHO. (2018). Malnutrition. NewsroomFactsheet. World Health Organisation: adapted from https://www.who.int/newsroom/fact-sheets/detail/malnutrition.

Retrieved on 26th June, 2019.

World Health Organization. (1995). Physical status: The use of and interpretation of anthropometry, Report of a WHO Expert Committee.

World Health Organization. (2010). Nutrition Landscape Information System (NLIS) country profile indicators: interpretation guide. 